\title{
Myths, facts and conditional truths: What is the evidence on the risks associated with smoking in cars carrying children?
}

\author{
Ray Pawson PhD, Geoff Wong MD(Res), Lesley Owen PhD
}

Competing interests: None declared.

This article has been peer reviewed.

Correspondence to: Professor Ray Pawson, r.d.pawson@leeds.ac.uk

CMAJ 2011. DOI:10.1503 /cmaj.100903
$\mathrm{T}$ he $C M A J$ recently carried a spirited exchange on the dangers to children exposed to second-hand smoke in cars. MacKenzie and Freeman showed how an unsubstantiated statistic (that second-hand smoke was 23 times more toxic in a vehicle than in a home) had acquired mythical status thanks to widespread circulation in the mass media and academic literature. ${ }^{1}$ Strasberg responded in a letter to the editor, concerned that MacKenzie and Freeman may create a counter-myth because their paper could be used to undermine laws banning smoking in cars carrying children. ${ }^{2}$ Peace broke out in Mackenzie and Freeman's rejoinder, "We unreservedly concur with Dr. Strasberg's position on the importance of raising awareness of the indisputable health risks posed by exposure to second-hand smoke."2

Neither MacKenzie and Freeman nor Strasberg, however, settled the matter of the empirical estimation of risk to children exposed to second-hand smoke in cars. MacKenzie and Freeman cited a study that measured secondhand smoke in cars and found a mean concentration of respirable suspended particles measuring less than 2.5 microns in diameter of 272 $\mu \mathrm{g} / \mathrm{m}^{3}$ with windows closed and $51 \mu \mathrm{g} / \mathrm{m}^{3}$ with windows open. The authors compared these figures with safety guidelines from the US Environmental Protection Agency of $40 \mu \mathrm{g} / \mathrm{m}^{3}$

(unsafe for children) and $250 \mu \mathrm{g} / \mathrm{m}^{3}$ (hazardous for anyone). ${ }^{1}$ Strasberg cited evidence that found "in-car second-hand smoke particle concentrations to be up to 60 times greater than in a smoke-free home."2

These estimates differ widely, as do the chosen comparators. We hope to show that, although the relevant data are rich and complex, a simple conclusion is possible. The evidence does not show an absolute risk threshold because a range of environmental, biological and social factors contribute to the risk equation. The evidence does, however, uncover conditional truths, and the careful enunciation of each contributory condition is the task of public health science.

\section{Assembling the evidence}

Figure 1 illustrates the causal chain of toxicity and points to the predicament of researchers in trying to determine the risks involved. First is the matter of the pollutants under study. Secondhand smoke is a complex mixture of chemicals, many with potentially harmful effects on health, ${ }^{3}$ and its concentration in vehicles varies (e.g., under different conditions of volume, speed and ventilation). Second is prevalence, the extent of smoking within vehicles, which is also difficult to monitor closely in the private space of a moving vehicle. Third is exposure, which is defined by the amount of second-hand smoke inhaled by a child in cars and its extent compared with exposure in other environments. The fourth element in the causal chain is sensitivity. Although an increasing body of research exists indicating that children's bodies are more susceptible to second-hand smoke, the extent of this difference is a factor that needs to be inserted into the risk equation. The final element is health impact, which is difficult to determine because exposure to second-hand smoke in vehicles makes up only one component of a lifetime of exposure to different toxins and environmental hazards. ${ }^{4}$ However, greater understand- 
ing can be gained from scrutinizing the evidence on each element, and this paper presents a brief overview of some pivotal research.

\section{What toxicity levels are encountered in a car when a cigarette is smoked?}

A number of studies have attempted to measure, under different driving conditions, pollutant levels when smoking occurs in a vehicle. ${ }^{5-10}$ In most studies, a strategically located monitor of air quality recorded the fluctuations in levels of toxicity while a cigarette was smoked. The studies showed that levels of toxicity vary substantially with traffic conditions, climatic conditions, speed of vehicle, type of vehicle, duration of journey, number of passengers, number of smokers, number of cigarettes smoked, proximity of smoker and passenger, history of smoking in the car and ventilation conditions. Whether ventilation, such as open windows or use of air conditioning, makes a difference is a bone of contention between proponents and opponents of laws prohibiting smoking in cars carrying children, and we turn shortly to closer consideration of this matter.

Edwards and coauthors provide us with some typical data. ${ }^{5}$ In their study, the principal investigator drove a car with another investigator as a passenger, who smoked cigarettes under specified conditions. Data were collected using a SidePak AM510 (TSI Inc.), a portable monitor measuring mean levels of suspended particulate matter of less than $2.5 \mu$ in diameter $\left(\mathrm{PM}_{2.5}\right)$ over one-minute periods. The monitor was located on a child's booster seat in the backseat of the car at the approximate height of a small child's nose. Ambient air was monitored before the experiment began and in-car during the journey. Three cigarettes were smoked, the first with the window open and the cigarette held outside, the second with the window half open and the cigarette held inside and the third with all windows closed.

Mean $\mathrm{PM}_{2.5}$ levels were 199 (peak 217) $\mu \mathrm{g} / \mathrm{m}^{3}$ during smoking of the first cigarette, 162 (peak 181) $\mu \mathrm{g} / \mathrm{m}^{3}$ during the second cigarette and 2926 (peak 3645) $\mu \mathrm{g} / \mathrm{m}^{3}$ during the third cigarette. Fifteen minutes after the third cigarette was extinguished, the $\mathrm{PM}_{2.5}$ level was 631 $\mu \mathrm{g} / \mathrm{m}^{3}$ and did not return to the baseline level until almost 40 minutes after the cigarette had been put out. $\mathrm{PM}_{2.5}$ levels observed during smoking were many times higher than levels in ambient air (3-4 $\left.\mu \mathrm{g} / \mathrm{m}^{3}\right)$ that were measured next to a busy traffic roundabout. The study showed considerable variation of toxicity among the different smoking conditions, but these variations are marginal compared with the almost thousand-fold difference between the measurements taken in ambient air and during smoking with windows closed.

\section{Does ventilation make a difference?}

All of the studies cited above indicated that pollutant concentrations decreased when the driver opened windows or used air conditioning. This "ventilation solution" has for some time been part of the argument of lobbyists for smokers' rights. The best evidence available to settle this debate is found in a study by Ott and colleagues that involved more than a hundred measures of air change in a variety of vehicles under differing ventilation and driving conditions. ${ }^{7}$ Table 1 summarizes the authors' key findings.

The study by Ott and coworkers showed that air change affected the presence of toxins, although the removal of toxins varied according to molecular structures (heavier and more dangerous particles are harder to remove). ${ }^{7}$ The study provides further evidence of the high level of contaminants that are present when smoking occurs in a vehicle with the windows closed. We also have provisional evidence in the middle rows of Table 1 of the fall in levels of contaminants under ventilated circumstances. Knowledge is advanced, but the risk calculation is not settled. We are still short of a benchmark to indicate whether any of the reported levels may be declared safe or dangerous, and we have merely opened the argument about how human activity (e.g., opening windows) can modify exposure.

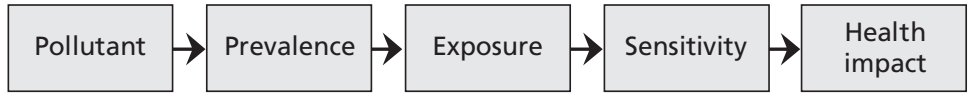

Figure 1: Causal chain of toxicity.

Table 1: Particulate concentrations under different driving and ventilation conditions

\begin{tabular}{|c|c|c|c|c|}
\hline \multirow{2}{*}{$\begin{array}{l}\text { Speed, } \\
\text { mph }\end{array}$} & \multirow[b]{2}{*}{ Windows position } & \multirow[b]{2}{*}{$A C$ or vents } & \multicolumn{2}{|c|}{$\mathrm{PM}_{2.5}\left(\mu \mathrm{g} / \mathrm{m}^{3}\right)$} \\
\hline & & & Max & Mean \\
\hline 20 & Closed & AC max & 3184 & 1113 \\
\hline 20 & Passenger window fully open & $A C$ off & 371 & 97 \\
\hline 60 & Passenger window open 3 inches & $A C$ off & 608 & 119 \\
\hline 60 & Closed & Vents off & 3212 & 1150 \\
\hline $\begin{array}{l}\mathrm{AC}=\text { air } \\
\mathrm{PM}_{2.5}=\mathrm{sL} \\
\text { Adapted }^{\text {2008. }}\end{array}$ & $\begin{array}{l}\text { nditioning, max = maximum, } \mathrm{mph}=\text { miles } \\
\text { pended particulate matter of less than } 2.5 \\
\text { y permission from Macmillan Publishers Lt }\end{array}$ & $\begin{array}{l}\text { in hour, } \\
\text { in diameter. } \\
\text { Ott et al. J Ex }\end{array}$ & SciE & Epidemiol \\
\hline
\end{tabular}


What are the levels of exposure?

A study by Leatherdale and Ahmed contains this illustrative description of children's exposure to smoking in cars: "In 2006, 28.1\% (810 000) of Canadian youth in grades 5-12 were exposed to smoking while riding in a car at least once in the previous week and 4.6\% (131 300) were exposed to smoke while riding in a car on a daily basis."

The crucial question is whether such exposures contribute to ill health. Evans and Chen's research into the association between environmental tobacco smoke in the home and vehicle and chronic bronchitis provides a typical example. ${ }^{4}$ The study, which relied on data produced in the 2005 Canadian Community Health Survey, discovered the following:

The proportion of respondents who reported ETS [environmental tobacco smoke] exposure in the home and vehicle was $9.0 \%$ and $8.4 \%$, respectively. The prevalence of self-reported doctor diagnosed chronic bronchitis was $1.5 \%$. When considered separately, home and vehicle ETS were both significantly associated with chronic bronchitis in children and adolescents aged 12-19 years. ... When home and vehicle ETS exposure were considered together, and sex, age, allergies, marital status, level of education and race were controlled for, home ETS exposure was not a significant predictor of chronic bronchitis ... while vehicle ETS was. ${ }^{4}$

The study shows an interesting and intricate web of associations, but can the results be regarded as conclusive? With this inquiry we encounter the most profound and limiting methodologic issue - complexity itself. The task of the researcher is to assess the contribution of one microenvironment, itself consisting

\section{Incomplete knowledge is no reason for postponing policy decisions.}

of multiple vehicle trips taken over many years and under many conditions, comparing it with a lifetime of irregular exposure to many equally complex air-quality environments, and then attempting to discover the onward influence of the former on a person's health profile, a complex dynamic in itself responding to many influences other than air quality.

Even the most powerful longitudinal research system could not track all of these pathways, and Evans and Chen had to rely on retrospective survey data with all the attendant problems of selfreport and memory. ${ }^{4}$ Bias caused by misclassification of exposure may have been present in this study, because participants with active respiratory symptoms and a formal diagnosis have more cause to recall exposure to environmental tobacco smoke. ${ }^{12}$

\section{Are the risks comparable to those of other environments in which smoking bans already operate?}

Precedents play a key part in law-making under a simple rationale - if intervention was needful there, then surely the same applies here. This sentiment is frequently used by lobbyists for the banning of smoking in cars carrying children, and the smoky bar, the bête noir of many public health advocates, is a much-used comparator. Edwards and coauthors ${ }^{13}$ studied the air quality in 604 pubs in different communities before the introduction of smoking bans in these establishments. As with in-car measurements, the measurements taken in this study showed large variations in air quality according to variables such as location of the pub, usage, time of week and time of day. The mean $\mathrm{PM}_{2.5}$ across all sites was 285.5 (range 54.1-1395.1) $\mu \mathrm{g} / \mathrm{m}^{3}$ with a mean of $399.4 \mu \mathrm{g} / \mathrm{m}^{3}$ in the worst cases (pubs in deprived areas). The reported peak levels are formidable, as stated by the authors: "The very high levels of over $1000 \mu \mathrm{g} / \mathrm{m}^{3} \ldots$ show how poor air quality can be in the smokiest venues."

However, drawing parallels on air quality across the two situations is not straightforward. In studies of in-car smoking, peak levels of particulate concentrations in vehicles that are not ventilated are over $3000 \mu \mathrm{g} / \mathrm{m}^{3}{ }^{3,7}$ If a comparison is drawn with mean levels in a wellventilated vehicle, Ott and coworkers' measure at $97 \mu \mathrm{g} / \mathrm{m}^{3}$ is lower than the means in any of the pubs. ${ }^{7,13}$ As toxic environments, both cars and pubs vary widely according to context and usage. One crucial difficulty is the matter of duration of exposure. Much of the evidence reports on "mean prevalence" and thus refers to quite different time intervals and circumstances. In a vehicle, this mean typically registers air quality during the smoking of a single cigarette. In a pub, the mean records the contributions of many smokers over an extended period of time. Much of the argument for banning smoking in such venues was that high levels of contaminants persisted over the cumulative work shifts of the bartender. Therefore, one can conclude that contamination can be greater in either pubs or vehicles, depending on the circumstances.

\section{How does risk compare with formally approved standards of air quality?}

One option for gauging the risk associated with in-vehicle smoking is to compare it with the formal standards of air quality recognized by offi- 
cial agencies. But this is a crucible in which science and politics mix precariously.

MacKenzie and Freeman used the "primary standards" put in place by the US Environmental Protection Agency in its safety guidelines. ${ }^{1,14}$ Primary standards are intended to set limits to protect public health, including the health of vulnerable populations such as people with asthma, children and the elderly. The safety guidelines limit levels of $\mathrm{PM}_{2.5}$ in ambient air to $15 \mu \mathrm{g} / \mathrm{m}^{3}$ annually and $35 \mu \mathrm{g} / \mathrm{m}^{3}$ in a 24 -hour period. ${ }^{14}$

If a child makes routine trips in a vehicle with peak mean exposure during smoking of about $3000 \mu \mathrm{g} / \mathrm{m}^{3}$, the recommended limits will be exceeded. This comparison seemingly establishes a firmer footing for evidence of harm, although there are provisos. The guidelines of the US Environmental Protection Agency are summative and cumulative. They set standards for the totality of toxins in all ambient conditions and are not intended to adjudicate on the momentary details of exposure in microenvironments, such as the rear seat of vehicles. The difference is that the cited studies that measured pollutant levels in second-hand smoke in vehicles focused on momentary and short-term prevalence $;^{5-10}$ the guidelines of the US Environmental Protection Agency concentrate instead on the dangers of repeated, long-term exposure.

Consider next a statement from the US Surgeon General on primary standards: "The scientific evidence indicates that there is no risk-free level of exposure to second-hand smoke."3 Under this benchmark, we should move from strong to unequivocal support to ensure that no child is ever exposed to second-hand smoke. But how is this zero magnitude to be explained and should it be regarded as authoritative? It transpires that the zero-tolerance standard is underpinned by a fundamental change in the interpretation of "risk."

In academic toxicology, Paracelsus' ancient maxim, often rendered "the dose makes the poison," posits that a substance becomes poisonous only when ingested at above some safe level. ${ }^{15}$ Historically, the Paracelsus principle has been considered the cornerstone of standard setting in public health.

More recently, an alternative credo, the "precautionary principle," has emerged, which asserts that when an activity raises threats of harm to human health, preventive measures should be taken even if some cause-and-effect relationships are not fully established. The US Surgeon General's new standard and the most recent benchmarks published by the World Health Organization are based on this imperative

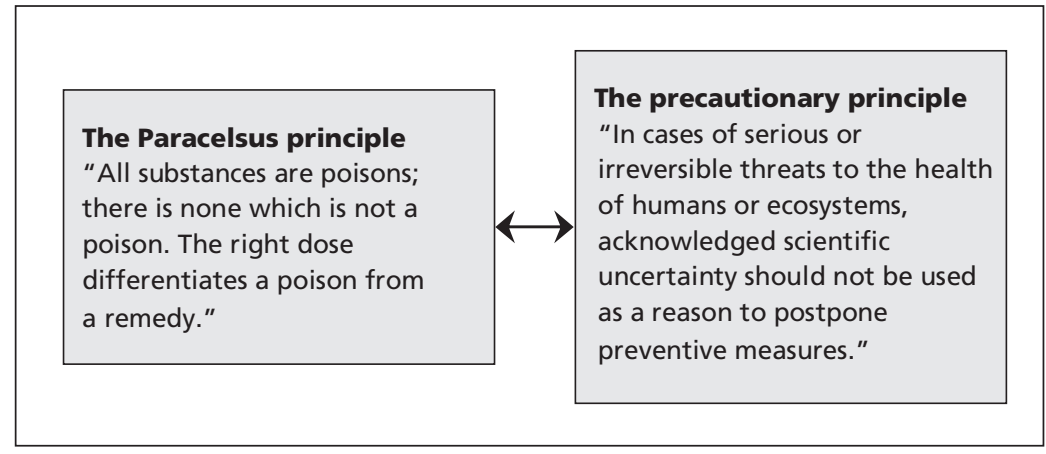

Figure 2: Two principles collide: the Paracelsus principle has historically been used to set standards in public health, but more recent benchmarks have been based on the precautionary principle.

(Figure 2). ${ }^{3,16}$ A discussion of the relative merits of the precautionary principle is beyond the scope of this paper; however, its very existence allows us to reiterate our main point. Calculations of risk are complex, and to reduce them to single magnitudes (be they tall, small or zero) is to leave them prey to political advocacy.

\section{Evidence to proceed}

Incomplete knowledge is no reason for postponing policy decisions or short-circuiting them via the installation of absolutist regulatory edicts. There is an abundance of evidence to help legislators decide on this matter, but that evidence always consists of conditional truths. Policy based on science and evidence has to exist amid uncertainty, and this is managed by acknowledging the contingencies. Thus, i) because of the confirmed cabin space, and ii) under the worst ventilation conditions, and iii) in terms of peak contamination, the evidence permits us to say that smoking in cars generates fine particulate concentration that are, iv) very rarely experienced in the realm of air-quality studies, and that will thus constitute a significant health risk because, v) exposure to smoking in cars is still commonplace, and vi) children are particularly susceptible and vii) are open to further contamination if their parents are smokers.

There is good enough evidence to make a balanced judgment and thus to legislate in a distinctly even-handed way.

\section{References}

1. MacKenzie R, Freeman B. Second-hand smoke in cars: How did the "23 times more toxic" myth turn into fact? CMAJ 2010;182:796-9.

2. Strasberg S. Re: Second-hand smoke in cars: How did the "23 times more toxic" myth turn into fact? [letter]; authors' reply. Available: www.cmaj.ca/lookup/eletters/182/8/796 (accessed 2010 June 29).

3. US Surgeon General. Children and secondhand smoke exposure - excerpts from the health consequences of involuntary exposure to tobacco smoke. A report of the Surgeon General. Atlanta (GA): US Department of Health and Human Services; 2007.

4. Evans J, Chen Y. The association between home and vehicle 
environmental tobacco smoke (ETS) and chronic bronchitis in a Canadian population: the Canadian Community Health Survey, 2005. Inhal Toxicol 2009;21:244-9.

5. Edwards R, Wilson N, Pierse N. Highly hazardous air quality associated with smoking in cars: New Zealand pilot study. $N Z$ Med J 2006;119:U2294.

6. Jones MR, Navas-Acien A, Yuan J, et al. Secondhand tobacco smoke concentrations in motor vehicles: a pilot study. Tob Control 2009; 18:399-404.

7. Ott W, Klepeis N, Switzer P. Air change rate of motor vehicles and in-vehicle pollutant concentrations from second-hand smoke. J Expo Sci Environ Epidemiol 2008;18:312-25.

8. Rees VW, Connolly GN. Measuring air quality to protect children from secondhand smoke in cars. Am J Prev Med 2006;31: 363-8.

9. Sendzik T, Fong GT, Travers MJ, et al. An experimental investigation of tobacco smoke pollution in cars. Nicotine Tob Res 2009; 11:627-34.

10. Vardavas C, Linardakis M, Kafatos A. Environmental tobacco smoke exposure in motor vehicles: a preliminary study. Tob Control 2006; $15: 415$.

11. Leatherdale ST, Ahmed R. Second-hand smoke exposure in homes and in cars among Canadian youth: current prevalence, beliefs about exposure, and changes between 2004 and 2006 Cancer Causes Control 2009;20:855-65.

12. Hu A. Exposure misclassification bias in studies of environmental tobacco smoke and lung cancer. Environ Health Perspect 1999;107:873-7.

13. Edwards R, Hasselholdt C, Hargreaves K, et al. Levels of second hand smoke in pubs and bars by deprivation and food-serving status: a cross-sectional study from North West England. BMC Public Health 2006;6:42.

14. U.S. Environmental Protection Agency. National ambient air quality standards. Washington (DC): The Agency; 2010. Avail- able: www.epa.gov/air/criteria.html (accessed 2010 Aug. 11).

15. Pagel W. Paracelsus: an introduction in philosophical medicine in the era of the renaissance. Basel $(\mathrm{CH})$ : Karger; 1982.

16. World Health Organization. Air quality guidelines for particulate matter, ozone, nitrogen dioxide and sulfur dioxide: summary of risk assessment. Geneva $(\mathrm{CH})$ : The Organization; 2005.

Affiliations: From the School of Sociology and Social Policy (Pawson), University of Leeds, Leeds, UK; the Department of Primary Care and Population Health (Wong), University College London, London, UK; and the National Institute for Health and Clinical Excellence (Owen), London, UK

Contributors: All of the authors conceived of the paper and acquired, analyzed and interpreted the data. Ray Pawson drafted the article, which Geoff Wong and Lesley Owen revised critically for important intellectual content. All of the authors approved the final version submitted for publication.

Funding: No specific funding was provided for this paper. The authors are currently receiving payment from the United Kingdom's Economic and Social Science Research Council to undertake a realist review of the use of legislation in public health. The data synthesized for the realist review formed part of the evidence cited in this paper. Geoff Wong holds a Clinical Lectureship that is funded by the United Kingdom National Institute of Health Research. Lesley Owen is an employee of the United Kingdom National Institute of Health and Clinical Excellence. The opinions expressed in this paper are those of the authors and not necessarily those held by their funding bodies or employers. 